Diabetologia (1994) 37: 911-916

\title{
Presence and further development of retinal dysfunction after 3-year follow up in IDDM patients without angiographically documented vasculopathy
}

\author{
M.A.S. Di Leo ${ }^{1}$, S. Caputo ${ }^{1}$, B. Falsini ${ }^{2}$, V. Porciatti ${ }^{3}$, A. V. Greco ${ }^{1}$, G. Ghirlanda ${ }^{1}$ \\ ${ }^{1}$ Department of Internal Medicine, Catholic University of Sacred Heart, Rome, Italy \\ ${ }^{2}$ Department of Ophthalmology, Catholic University of Sacred Heart, Rome, Italy \\ ${ }^{3}$ Institute of Neurophysiology, National Council of Research, Pisa, Italy
}

Summary Abnormalities in neuroretinal function may play a role in the development of diabetic retinopathy. The natural course of diabetic retinal dysfunction in a group of subjects with insulin-dependent diabetes mellitus and with no apparent microvascular alterations in the retina was followed-up with fluorescein angiography and a sensitive electrophysiological technique, i.e., steady-state focal electroretinogram at the macula, for 3 years. Before the beginning and throughout our study, strict glycaemic control was maintained by three or four daily insulin injections under careful monitoring. Analysis of macular electroretinogram provided information from different neural layers. At the first examination, functional activities of postreceptoral neurons were significantly decreased with respect to those of age-matched control subjects. Diabetic patients showed a functional loss of both ganglion cell $(0.53 \pm 0.09$ vs 0.42 $\pm 0.11 \mu \mathrm{V} ; t=5 ; p=0.0001)$ and preganglion cell
$(0.51 \pm 0.13$ vs $0.42 \pm 0.14 \mu \mathrm{V} ; t=2.8 ; p=0.007)$ layers. Diabetes did not alter photoreceptor activity. After 3 years, dysfunction was significantly greater in the preganglion cell layer $(0.28 \pm 0.11 \mu \mathrm{V} ; t=6.3$; $p=0.0001)$. Although in some patients further impairment of ganglion cell function was shown, no significant difference was found in 3 years. Photoreceptor function remained unaltered. No vascular abnormalities in the retina were noted after 3 years in this group of patients. Metabolic control was not correlated to functional changes. Our findings suggest that the middle retinal layer is the most sensitive physiological locus of progressive diabetes-induced dysfunction in the absence of angiographically documented abnormalities. [Diabetologia (1994) 37: 911-916]

Key words Retinal function, focal electroretinogram, inner retina, photoreceptors, intensive insulin therapy, diabetic retinopathy, follow-up.
The sequence of early retinal changes in diabetes is poorly defined. Clinically detectable retinopathy in subjects with IDDM develops many years after the onset of the disease. Diabetic retinopathy has traditionally been attributed to microvascular changes [1]. Little attention has been directed to the effects of diabetes on the neural retina comprised of differ-

Received: 27 December 1993

and in revised form: 4 April 1994

Corresponding author: Professor G. Ghirlanda, Università Cattolica del Sacro Cuore, Istituto di Clinica Medica, Largo A. Gemelli 8, I-00168 Rome, Italy

Abbreviations: IDDM, insulin-dependent diabetes mellitus; $\mathrm{ERG}$, electroretinogram. ent cell layers and of the optic visual pathway. An important question is whether the mechanisms underlying the disturbances of the diabetic retina may or may not affect retinal neurons earlier than the vessels of the microcirculation. It is presumed that the initial pathological changes which occur in the small vessels of the diabetic retina include endothelial cell and pericyte damage as a result of trypsin digest techniques $[2,3]$ and the breakdown of the blood-retinal barrier detected by vitreous fluorophotometry [4]. However, there are contradictory results about the documentation of these early morphologic findings [5-7] and the pathogenetic importance of these abnormalities is unclear [8]. Recently, an experimental study showed an absence of microaneurysms, acellular capillaries, or pericyte ghosts in 
Table 1. Clinical characteristics of the diabetic subjects

\begin{tabular}{ll}
\hline & Diabetic subjects \\
\hline$n$ & 21 \\
Sex (male/female) & $8 / 13$ \\
Age (years) & $19.7 \pm 8.3$ \\
Age at diagnosis (years) & $17.5 \pm 8$ \\
Duration of disease (years) & $2.3 \pm 3.1$ \\
HbA $_{1 \mathrm{c}}$ (\%) & $6.4 \pm 1.7$ \\
${\text { Mean 3-year } \mathrm{HbA}_{1 \mathrm{c}}(\%)}$ & $6.9 \pm 1.4$ \\
\hline
\end{tabular}

Values are means \pm SD

small retinal vessels at a very early stage of retinopathy [9].

Over the past few years, the neuro-ophthalmologic use of clinical electrophysiology seems to have somewhat modified the view that the initial insult to the diabetic retina is a microangiopathy. Bresnick [10] has suggested the occurrence of an early neurosensory disorder in the diabetic retina, according to previous data from psychophysical [11-14] and electrophysiological [15-19] studies. However, not all investigators have found functional changes before the appearance of vasculopathy in the diabetic retina [20-22].

Using a more sensitive steady-state ERG rather than a transient ERG, early and possibly reversible signs of visual alterations in retinal function have been detected after a few years of diabetes, when no microvascular changes were could be found [23-27]. To investigate further the specific period in which ERG changes could precede the appearance of diabetic vasculopathy in the retina, we prospectively studied the function of all retinal neuron layers using steady-state focal ERG of the macula in diabetic patients on entry into the study and again after 3 years.

\section{Subjects and methods}

Subjects. Twenty-one IDDM patients (aged 5 to 38 years) were studied. No retinopathy was found on fluorescein angiography before and after the longitudinal study, according to the first level of the Klein classification [28] (Table 1). Metabolic control was evaluated by measuring $\mathrm{HbA}_{1 \mathrm{c}}$ levels at the time of the first ERG examination and every 3 months thereafter. Excluded from the longitudinal study were patients who had been previously treated with two or less daily injections of insulin or who showed severe and recurrent hypoglycaemia. None of the patients had any eye or systemic diseases. Patients were asked to monitor blood glucose levels using a home blood glucose monitor three or four times per day for the 3-year follow-up. Strict glycaemic control was achieved by three or four daily insulin injections and monthly blood glucose measurements by physician.

The control group consisted of 25 age- and sex-matched subjects ( 12 men, 13 women, mean age 21 , SD 6 years) with no family history of diabetes. Since macular ERG amplitude decreases late in life, as previously reported [29, 30] showing that age may mildly affect neuroretinal function, a focal ERG was also obtained in all control subjects after 3 years.

Informed consent was obtained from each subject.
Methods. Clinical examination (segment biomicroscopy, corrected visual acuity, applanation tonometry, direct and indirect ophthalmoscopy) was carried out on each subject. Stereofundus photography and fluorescein angiography were performed on each patient initially and after 3 years.

Fluorescein angiography was performed initially and after 3 years with a professional $50^{\circ}$ fundus camera after a rapid 5 -ml injection of $10 \%$ fluorescein sodium into the antecubital vein. Angiograms were taken with ASA400 black-and-white film.

At the beginning and at the end of this longitudinal study, we used focal ERG by uniform field (flicker ERG, FERG) and alternating black-and-white bar stimuli (pattern ERG, PERG), as previously reported [25]. FERG analysis yields a first (1F) and second (2F) component; PERG only has a second component (2P) [31-34]. 1F originates in the photoreceptor layer, whereas $2 \mathrm{~F}$ and $2 \mathrm{P}$ represent subsets of generators in the inner retina. $2 \mathrm{P}$, but not $2 \mathrm{~F}$, is correlated to ganglioncell function $[34,35]$. A recent study has provided evidence that the $2 \mathrm{~F}$ component, unlike $2 \mathrm{P}$, has multiple generators in the middle-to-inner retina and that $2 \mathrm{~F}$ and $2 \mathrm{P}$ may originate, at least in part, from the same retinal layer(s) [36]. Briefly, alternating black-and-white bars had a 1.7 eyele/degree spatial frequency, a temporal frequency of $8 \mathrm{~Hz}$. In our experiments the stimulus area for PERG and FERG was set at about 80 degrees $^{2}$ (a square of $9 \times 9$ degree centred on the fovea) at which 2P, $1 \mathrm{~F}$ and $2 \mathrm{~F}$ components have approximately similar amplitudes [35]. Since we wanted to compare the PERG with the FERG elicited from the same retinal area, the flicker stimulus was surrounded by a background of comparable luminance in order to reduce the effects of stray light. Under these conditions FERG can be considered focal in nature [37]. To evaluate the $1 \mathrm{~F}$ component we used a more suitable temporal frequency of $32 \mathrm{~Hz}$ [35].

All subjects were able to maintain fixation from a $43-\mathrm{cm}$ viewing distance on a black mark placed in the centre of the stimulus. Pupils were not dilated and had been previously measured (pupil sizes of control and diabetic subjects were not significantly different at the moment of the first ERG test and after 3 years). ERGs were monocularly recorded by means of commercially available $\mathrm{Ag} / \mathrm{AgCl}$ electrodes taped over the skin of the lower eyelid. Another similar electrode placed over the eyelid of the contralateral unstimulated eye was used as reference (interocular ERG; [38]). Retinal signals were band-pass filtered between 1 and $100 \mathrm{~Hz}$, amplified 100,000 fold and averaged up to 800 responses by an IBM PC/XT computer, allowing rejection of single sweeps disturbed by artifacts. Discrete Fourier series of the averaged responses [39] were performed off-line to isolate the main harmonic components of PERG (i.e., $2 \mathrm{P}$ ), and FERG (i.e., $1 \mathrm{~F}$ and $2 \mathrm{~F}$ ). The peak-to-peak amplitude [in microvolts $(\mu V)]$ and phase in degrees of each of three components was evaluated. Each test was repeated at least twice to verify reproducibility. Amplitude and phase responses were simultaneously measured for FERG as successively for PERG. The average variation in amplitude between the two samples was $5 \%$; mean amplitudes of the early and late tests were not significantly different.

A fasting blood sample to measure $\mathrm{HbA}_{1 \mathrm{c}}$ values was drawn from each patient in the morning of the ERG tests and at 3-month intervals for the 3-year follow-up. $\mathrm{HbA}_{1 \mathrm{c}}$ was measured with an automated $\mathrm{HbA}_{1 c}$ analyser (HA 8110, Menarini Diagnostici, Firenze, Italy) by HPLC with $5.8 \%$ as the upper limit of the normal range. 
Table 2. Longitudinal focal ERG component results

\begin{tabular}{llll}
\hline & $1 \mathrm{~F}$ & $2 \mathrm{~F}$ & $2 \mathrm{P}$ \\
\hline $\begin{array}{l}\text { Control subjects } \\
\text { [baseline] }\end{array}$ & $1.0 \pm 0.34$ & $0.51 \pm 0.13$ & $0.53 \pm 0.09$ \\
$\begin{array}{l}\text { Control subjects } \\
\text { [3 years] }\end{array}$ & $0.95 \pm 0.26$ & $0.51 \pm 0.11$ & $0.52 \pm 0.06$ \\
$\begin{array}{l}\text { Diabetic subjects } \\
\text { [baseline] }\end{array}$ & $0.86 \pm 0.36$ & $0.43 \pm 0.14$ & $0.42 \pm 0.11$ \\
$\begin{array}{l}\text { Diabetic subjects } \\
\text { [3 years] }\end{array}$ & $0.87 \pm 0.39$ & $0.28 \pm 0.11$ & $0.39 \pm 0.13$ \\
\hline
\end{tabular}

Values are means $\pm \mathrm{SD}$ in $\mu \mathrm{V}$

\section{Statistical analysis}

Results are presented as means \pm SD. Before statistical analysis, we calculated the intereye correlation for each subject. We considered only the right eye amplitudes in control subjects, because the paired eyes were positively correlated. On the contrary, the inter eye correlation in our diabetic group was not significant. We therefore used a two-eye statistical analysis according to Ederer [40] and Ray and O'Day [41], because paired eyes contribute the same amount of information as unpaired eyes. Unpaired Student's $t$-test, paired $t$-test, and multiple and linear regression analyses were also used.

\section{Results}

At the time of the first and the last tests there was no significant difference between diabetic and control groups for sex and age.

At the beginning of the study and after the period of 3 years, no microvascular abnormalities were found in diabetic subjects by fluorescein angiography.

Table 2 shows that the mean $2 \mathrm{~F}$ and $2 \mathrm{P}$ component responses after the first test were significantly reduced in diabetic patients compared with the control group (2F: unpaired $t$ test $=2.8, p=0.007 ; 2 \mathrm{P}: t=5$, $p=0.0001) ; 1 \mathrm{~F}$ was not significantly altered. After 3 years, means of focal ERG components in the non-diabetic group were not significantly reduced (paired $t=1.8 ; p=\mathrm{NS}$ ). The mean $2 \mathrm{Famplitude}$ of diabetic patients (paired $t=6.3 ; p=0.0001$ ), but not the mean $2 \mathrm{P}$ amplitude of the same group, was significantly reduced. Figure 1 shows $2 \mathrm{~F}$ and $2 \mathrm{P}$ findings in each eye of the diabetic patients. Although there is also a trend towards visual function impairment for $2 \mathrm{P}$ component, many ganglion cell activities of diabetic eyes had only slightly deteriorated after 3 years. No significant modification of $1 \mathrm{~F}$ responses in each eye of the diabetic patients was found at 3 years (Fig. 2). Figure 3 shows that variations of $2 \mathrm{~F}$ responses were significantly correlated with those of $2 \mathrm{P}$ recordings $(r=0.39, p<$ $0.0001)$. No correlation was found between $\mathrm{HbA}_{1 \mathrm{c}}$ values and responses of PERG and FERG.

No significant differences in each component phase were noted in normal and diabetic subjects either before or after the 3-year follow-up.

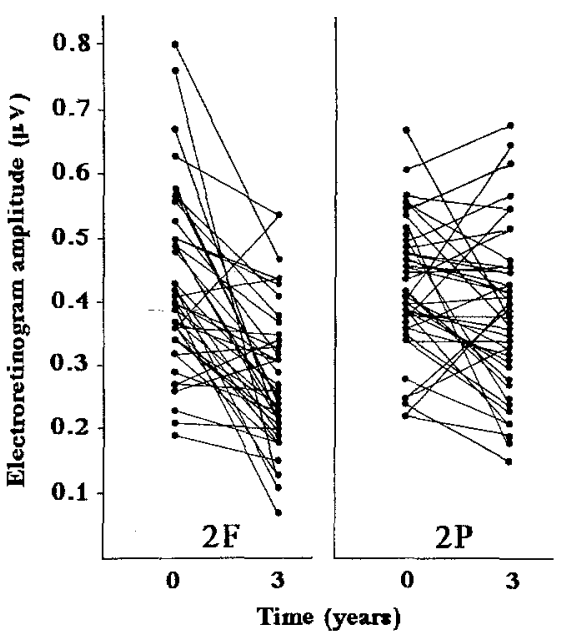

Fig. 1. $2 \mathrm{~F}$ and $2 \mathrm{P}$ amplitudes in each eye of the diabetic patients at the first test with focal ERG and at the second test after 3 years

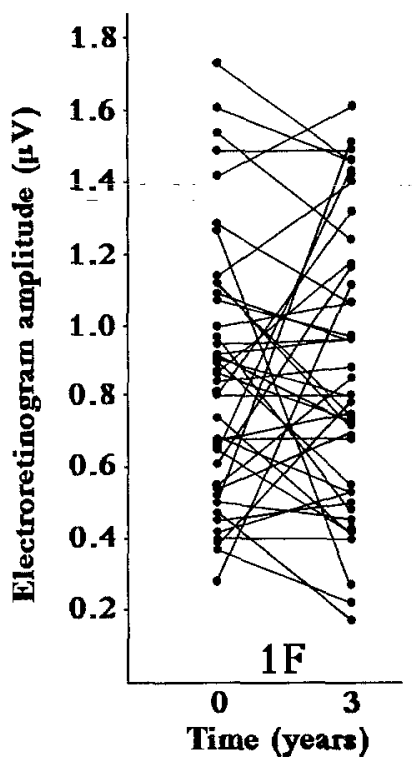

Fig. 2. 1F amplitude in each eye of the diabetic patients at the first test with focal ERG and at the second test after 3 years

\section{Discussion}

The retina is a complex structure comprising two different vascular systems and several neural layers, including retinal pigment epithelium, photoreceptors, bipolar cells, ganglion cells, and other neurons. Although diabetic retinopathy is frequently considered a vasculopathy, the vascular component is only a small portion of the retina. This consists mainly of neural tissue, the activity of which is revealed by ERG techniques. With focal ERG, it is possible to provide information from the central retina, i.e., the macula, which has higher neuronal density than peripheral retina [32-34]. Some papers have shown that the pattern and focal ERG can become abnormal in diabetes before the onset of any visible vasculopathy 
914

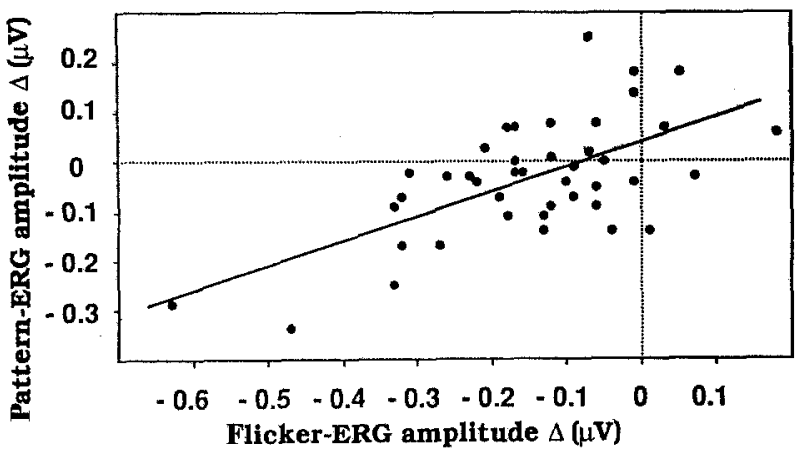

Fig. 3. Relationship between $\Delta$ [3-year amplitude - baseline amplitude] components of steady-state focal ERG for each diabetic eye. The analysis of ERG in response to counterphase-modulated sinusoidal gratings [pattern-ERG] and to luminance modulation of a uniform field [flicker-ERG] on the monitor yields component amplitudes which are correlated to ganglion cell and bipolar and/or amacrine cell functions, respectively. Solid line, linear regression for the data $(y=0.5$ $x=0.04)$.

[23-27]. Experimental [32, 42] and clinical [32-34] studies showed that $1 \mathrm{~F}, 2 \mathrm{~F}$, and $2 \mathrm{P}$ components of a steady-state focal ERG arise from different retinal neurons. Using this technique, which was first performed in different retinal disorders [35], we have found a gradual loss of postreceptor neuronal function as a result of diabetes, despite intensive insulin therapy and good metabolic control as reported by mean $\mathrm{HbA}_{1 \mathrm{c}}$ levels during the 3-year follow-up.

On the other hand, although the benefits of intensive therapy with respect to conventional therapy are unquestionable [43], irreversible or transient worsening of retinopathy can be found, as described in previous studies $[44,45]$. The three component phases were unchanged throughout this investigation, and although the $2 \mathrm{~F}$ phase tended to be delayed in our patients, its mean values were not statistically different in IDDM and control subjects.

Retinal function impairment may be related to a higher incidence of hypoglycaemic episodes in our intensive-therapy diabetic patients. Hypoglycaemia is potentially dangerous because the tissues of the central nervous system are exclusively dependent on glucose as a metabolic fuel [46]. Some studies have shown neurophysiological alterations during and immediately after the hypoglycaemic period [47, 48]. The possibility that repeated hypoglycaemic episodes may impair glucose utilization in the inner retina (as revealed by a decrease of $2 \mathrm{~F}$ and $2 \mathrm{P}$ amplitudes), without diminishing the activity of photoreceptors which receive a higher blood flow from the choroidal circulation cannot be ruled out. Recently, Skrandies and Heinrich [49] found an increase of ERG amplitude correlated to photoreceptors in reponse to hypoglycaemia.

In this study, the duration of follow-up could be too short to detect long-term effects of near-normo-
M.A.S. Di Leo et al.: Progressive retinal dysfunction in diabetes

glycaemia on both the deterioration of retinal neuron activity and the development of diabetic retinopathy. Engerman and Kern [50] found that the appearance of retinopathy in diabetic dogs was not related to present control but to previous hyperglycaemia. The findings of this study may provide information about the long phase preceding diabetic retinopathy: a silent process in the diabetic retina which may involve both neural and vascular structures persists for several years before clinical vasculopathy can be detected. Whether neuroretinal abnormalities may in turn lead to an increased vulnerability of the retinal microvasculature in diabetes is to be ascertained. A recent study ascribed the development of diabetic vasculopathy in the retina to abnormalities of the surrounding milieu [51].

Some authors concluded on the basis of the techniques used, that vascular alterations in the diabetic retina were an earlier event than neurosensory dysfunction $[52,53]$. However, in diabetic animals some authors found evidence that the disease affects retinal metabolism independently from vascular disease $[54,55]$. Until now, the inability to clinically demonstrate neural abnormalities in the diabetic retina may be due to inadequacy of the means at our disposal. Improvement in electrodiagnostic tests can allow clinical recording of both the electrical response of the entire retina and the neuronal activities of distinct layers (receptoral to post-receptoral).

Further studies performed on larger numbers of patients and longer-term follow-up may provide more information on this relationship.

In conclusion, our study suggests that in IDDM patients under strict metabolic control neuronal function of the innermost retina before clinically detectable vascular abnormalities occurred was surprisingly impaired after only a few years of disease. It remains unclear whether the retinal dysfunction found in eyes with angiographically normal fundus represents a stage of pre-retinopathy related either to focal regions with non-vascular metabolic abnormalities or to localised areas of invisible defective capillary circulation.

\section{References}

1. Davis MD (1992) Diabetic retinopathy. Diabetes Care 15:1844-1874

2. Kuwabara T, Cogan DG (1960) Retinal vascular patterns. I. Normal architecture. Arch Ophthalmol 64:904-911

3. Engerman RL, Davis MD, Bloodworth JMB (1971) Retinopathy in experimental diabetes: its relevance to diabetic retinopathy in man. In: Rodriguez $\mathrm{R}$, Vallance-Owen J (eds) Diabetes. Excerpta Medica, Amsterdam, pp 261267

4. Cuhna-Vaz JG, Faria de Abreu JR, Campos AJ, Figo GM (1975) Early breakdown of the blood-retinal barrier in diabetes. Br J Ophthalmol 59:649-656 
5. Kamijo M, Cherian PV, AAF Sima (1993) The preventive effect of aldose reductase inhibition on diabetic optic neuropathy. Diabetologia 36:893-898

6. Chahal PS, Chowienczyk PJ, Kohner EM (1985) Measurement of blood-retinal barrier permeability: a reproducibility study in normal eyes. Invest Ophthalmol Vis Sci 26:977-982

7. Krogsaa B, Lund-Andersen H, Mehlsen J, Sestoft L (1986) The blood-retinal barrier permeability to fluorescein in normal subjects and in juvenile diabetics without retinopathy. Acta Ophthalmol 64:173-179

8. Frank RN (1984) On the pathogenesis of diabetic retinopathy. Ophthalmology 91:626-634

9. Danis RP, Yang Y (1993) Microvascular retinopathy in the Zucker diabetic fatty rat. Invest Ophthalmol Vis Sci 34:2367-2371

10. Bresnick GH (1986) Diabetic retinopathy viewed as a neurosensory disorder. Arch Ophthalmol 104:989-990

11. Ghafour MI, Fould WS, Allan D, McClure E (1982) Contrast sensitivity in diabetic subjects with and without retinopathy. Br J Ophthalmol 66:492-495

12. Sokol S, Moskowitz A, Skarf B, Evans R, Molitch M, Senior B (1985) Contrast sensitivity in diabetics with and without background retinopathy. Arch Ophthalmol 103:51-54

13. Della Sala S, Bertoni G, Somazzi L, Stubbe F, Wilkins AJ (1985) Impaired contrast sensitivity in diabetic patients with and without retinopathy: a new technique for rapid assessment. Br J Ophthalmol 69:136-142

14. Di Leo MAS, Caputo S, Falsini B et al. (1992) Nonselective loss of contrast sensitivity in visual system testing in early type 1 diabetes. Diabetes Care 15:620-625

15. Cirillo D, Gonfiantini E, De Grandis D, Bongiovanni L, Robert JJ, Pinelli L (1984) Visual evoked potentials in diabetic children and adolescents. Diabetes Care 7:273-275

16. Bresnick GH, Korth K, Groo A, Palta M (1984) Electroretinographic oscillatory potentials predict progression of diabetic retinopathy. Arch Ophthalmol 102:1307-1311

17. Arden GB, Hamilton AMP, Wilson-Holt J, Ryan S, Yudkin JS, Kurtz A (1986) Pattern electroretinogram becomes abnormal when background diabetic retinopathy deteriorates to a preproliferative stage: possible use as a screening test. Br J Ophthalmol 70:330-335

18. Coupland SG (1987) A comparison of oscillatory potential and pattern electroretinogram measures in diabetic retinopathy. Doc Ophthalmol 66:207-218

19. Trick GL, Burde RM, Gordon MO, Kilo C, Santiago JV (1988) Retinocortical conduction time in diabetics with abnormal pattern reversal electroretinograms and visual evoked potentials. Doc Ophthalmol 70:19-28

20. Wanger P, Persson HE (1985) Early diagnosis of retinal changes in diabetes: a comparison between electroretinography and retinal biomicroscopy. Acta Ophthalmol 63:716-720

21. Trick GL, Burde RM, Gordon MO, Kilo C, Santiago JV (1988) Retinocortical conduction time in diabetics with abnormal pattern reversal electroretinograms and visual evoked potentials. Doc Ophthalmol 70:19-28

22. Nesher R, Trick GL (1991) The pattern electroretinogram in retinal and optic nerve disease. A quantitative comparison of the pattern of visual dysfunction. Doc Ophthalmol 77:225-235

23. Caputo S, Di Leo MAS, Falsini B et al. (1990) Evidence for early impairment of macular function with pattern electroretinogram in type $I$ diabetic patients. Diabetes Care $13: 412-418$

24. Di Leo MAS, Falsini B, Caputo S, Ghirlanda G, Porciatti V, Greco AV (1990) Spatial frequency-selective losses with pattern electroretinogram in type 1 (insulin-dependent) diabetic patients without retinopathy. Diabetologia 33:726-730

25. Ghirlanda G, Di Leo MAS, Caputo S et al. (1991) Detection of inner retina dysfunction by steady-state focal electroretinogram pattern and flicker in early IDDM. Diabetes 40:1122-1127

26. Juen S, Kieselbach GF (1990) Electrophysiological changes in juvenile diabetics without retinopathy. Arch Ophthalmol 108:372-375

27. Prager TC, Garcia CA, Mincher CA, Mishra J, Chu HH (1989) The pattern electroretinogram in diabetes. Am J Ophthalmol 109:279-284

28. Klein BEK, Davis MD, Segal P et al. (1984) Diabetic retinopathy: assessment of severity and progression. Ophthalmology $91: 10-17$

29. Porciatti V, Falsini B, Scalia G, Fadda A, Fontanesi G (1988) The pattern electroretinogram by skin electrodes: effect of spatial frequency and age. Doc Ophthalmol 70:117-122

30. Bagolini B, Porciatti V, Falsini B, Scalia G, Neroni M, Moretti $\mathrm{G}$ (1988) Macular electroretinogram as a function of age of subjects. Doc Ophthalmol 70:37-43

31. Maffei L, Fiorentini A (1981) Electroretinographic responses alternating gratings before and after section of the optic nerve. Science 211:953-955

32. Hess RF, Baker CJ (1984) Human pattern-evoked electroretinogram. J Neurophysiol 51:939-951

33. Porciatti V (1987) Non-linearities in the focal ERG evoked by pattern and uniform-field stimulation. Their variation in retinal and optic nerve dysfunction. Invest Ophthalmol Vis Sci 28:1306-1313

34. Baker CL, Hess RF, Olsen BT, Zrenner E (1988) Current source density analysis of linear and non-linear components of the primate electroretinogram. J Physiol 407:155-176

35. Porciatti V, Falsini B, Fadda A, Bolzani R (1989) Steadystate analysis of the focal ERG to pattern and flicker: relationship between ERG components and retinal pathology. Clin Vision Sci 4:323-332

36. Porciatti V, Falsini B (1993) Inner retina distribution to the flicker electroretinogram: a comparison with the pattern electroretinogram. Clin Vision Sci 8:435-447

37. Biersdorf WR (1989) The clinical utility of the foveal electroretinogram: a review. Doc Ophthalmol 73:313-325

38. Fiorentini A, Maffei L, Pirchio M, Spinelli D, Porciatti V (1981) The ERG in response to alternating gratings in patients with diseases of the peripheral visual pathways. Invest Ophthalmol Vis Sci 21:490-493

39. Fadda A, Falsini B, Neroni M, Porciatti V (1989) Development of a personal computer software for a visual electrophysiology laboratory. Comput Methods Programs Biomed 28:45-50

40. Ederer (1973) Shall we count numbers of eyes or numbers of subjects? Arch Ophthalmol 89:1-2

41. Ray WA, O'Day DM (1985) Statistical analysis of multieye data in ophthalmic research. Invest Ophthalmol Vis Sci $26: 1186-1188$

42. Berardi N, Domenici L, Gravina A, Maffei L (1990) Pattern ERG in rats following section of the optic nerve. Exp Brain Res 79:539--546

43. The Diabetes Control and Complications Trial Research Group (1993) The effect of intensive treatment of diabetes on the development and progression of long-term complications in insulin-dependent diabetes mellitus. $\mathrm{N}$ Engl J Med 329:977-986

44. Lauritzen T, Frost-Larsen K, Larsen HW, Deckert T (1983) Effect of 1 year of near-normal blood glucose levels on 
retinopathy in insulin-dependent diabetics. Lancet I:200204

45. Dahl-Jorgensen K, Brinchmann-Hansen O, Hanssen KF, Sandvik L, Aagenaes O (1985) Rapid tightening of blood glucose control leads to transient deterioration of retinopathy in insulin dependent diabetes mellitus: the Oslo study. BMJ 290:811-815

46. Cryer PE, Gerich JE (1985) Glucose counterregulation, hypoglycemia and intensive insulin therapy in diabetes mellitus. N Engl J Med 313:232-241

47. Hoffman RG, Speelman DJ, Hinnen DA, Conley KL, Guthrie RA, Knapp RK (1989) Changes in cortical functioning with acute hypoglycemia and hyperglycemia in type I diabetes. Diabetes Care 12:193-197

48. Tallroth G, Lindgren M, Stenberg G, Rosen I, Agardh C-D (1990) Neurophysiological changes during insulin-induced hypoglycaemia and in the recovery period following glucose infusion in type 1 (insulin-dependent) diabetes mellitus and in normal man. Diabetologia 33:319-323

49. Skrandies W, Heinrich H (1992) Differential effects of mild hypoglycemia on proximal and distal retinal structures in man as revealed by electroretinography. Neurosci Lett $134: 165-168$
50. Engerman RL, Kern TS (1987) Progression of incipient diabetic retinopathy during good glycemic control. Diabetes 36:808-812

51. Rand LI (1991) Diabetic retinopathy: can we modify its course? Am J Med 90 [Suppl 2A]:66S-69S

52. Bek T, Lund-Andersen H (1990) Localised blood-retinal barrier leakage and retinal light sensitivity in diabetic retinopathy. Br J Ophthalmol 74:388-392

53. Patel V, Rassam S, Newsom R, Wiek J, Kohner E (1992) Retinal blood flow in diabetic retinopathy. BMJ 305:678683

54. MacGregor LC, Rosecan LR, Laties AM, Matschinsky FM (1986) Altered retinal metabolism in diabetes. I. Microanalysis of lipid, glucose, sorbitol, and myo-inositol in the choroid and in the individual layers of the rabbit retina. $J$ Biol Chem 261:4046-4051

55. Sima AAF, Zhang WH, Cherian PV, Chakrabarti S (1992) Impaired visual evoked potential and primary axonopathy of the optic nerve in the diabetic BB/W-rat. Diabetologia 35:602-607 